\title{
INTEGRACIÓN Y DESARROLLO ECONÓMICO EN AMÉRICA CENTRAL: EL RENACER DE UN VIEJO DEBATE
}

\author{
José Briceño Ruiz*
}

Durante décadas la Comisión Económica para América Latina (CEPAL) propuso una estrategia de desarrollo dirigida a eliminar los problemas estructurales que impedían el avance económico de la región. La industrialización con sustitución de importaciones (ISI) constituyó el elemento central de esta estrategia aunque, como se evidencia en los primeros escritos cepalinos, no era concebida como un fin en si misma sino como un mecanismo para que la periferia se apropiase de los frutos del progreso técnico e incrementase su nivel de vida (Prebisch, 1949 [1996]: 117). Se entendía que la ISI ayudaría a resolver el problema de la baja elasticidad-precio de la oferta exportable de la periferia al permitirle auto-abastecerse de ciertos productos industriales, evitando un incremento de la oferta de sus exportaciones tradicionales para obtener mayores cantidades de bienes industriales y disminuyendo la presión sobre los precios de su oferta exportable.

La CEPAL proponía una mejor distribución de los frutos del progreso técnico, eliminando la industrialización autárquica con alta protección tarifaria implementada en algunos países latinoamericanos en los años veinte y treinta, que no permitía obtener economías de escala, y la excesiva protección arancelaria otorgada a las nuevas fábricas. Por ello intentó re-orientar la ISI mediante una política arancelaria "cuidadosa y selectiva" adaptable de forma continua a las nuevas realidades mundiales (Prebisch, 1959a: 269). Así, la integración era parte de una estrategia para superar las dificultades originadas por la ISI a escala nacional. Una industrialización autárquica y sin coordinación o complementación entre los países no era racional para producir bienes intermedios, intensivos en capital, que requerían mercados más amplios para establecer plantas con tamaño mínimo adecuado. Mediante la integración económica se podría, en cambio, crear industrias regionales capaces de producir bienes intermedios y de capital en condiciones competitivas, es decir, plantas de tamaño óptimo para obtener los beneficios de las economías de escala.

La necesidad creciente de bienes de capital, requeridos en la nueva fase de la ISI, exigía a los países latinoamericanos incrementar sus exportaciones o promover las inversiones extranjeras para adquirir nuevos equipos y maquinarias. Sin descartar estas alternativas, la CEPAL proponía que en la nueva fase de la ISI a nivel regional se diese preferencia a la producción de estos bienes de capital necesarios para continuar con las ulteriores etapas del proceso industrializador. La integración era entonces un proyecto de industrialización, con la meta no de alcanzar el libre comercio para todos los productos en breve tiempo sino de permitir que la producción de bienes de capital pudiera "realizarse progresivamente en el ámbito de un mercado común” (Prebisch, 1959b: 510).

La integración sería también un instrumento de planificación para aquellos países que aún no habían iniciado o que se encontraban en la fase inicial de su desarrollo industrial. Mediante la integración los países más pequeños de la región, como los centroamericanos y caribeños, podrían iniciar un proceso racional de industrialización. La pequeñez de sus mercados obstaculizaba incluso el desarrollo de industrias de bienes de consumo competitivas. La integración regional les permitiría establecer programas industriales comunes basados en principios de reciprocidad y equidad que permitiría una ISI orgánica y autónoma, cada vez menos dependiente de insumos extra-regionales.

La integración también era un mecanismo para incrementar la competitividad de la producción industrial latinoamericana. Diversos escritos de la CEPAL criticaron el excesivo sesgo proteccionista de las políticas de desarrollo industrial y la poca racionalidad de la protección otorgada. Se criticaban las políticas existentes por haber creado "una estructura industrial prácticamente aislada del mundo exterior", amparada en políticas de protección otorgadas sin moderación, sin considerar las condiciones de economicidad sino la factibilidad del proyecto industrial "cualquiera que fuese el costo de producción” (Prebisch, 1963: 86). Diversos estudios elaborados por la secretaría de la CEPAL denunciaron la inexistencia de una política coherente de

Magister en Relaciones Internacionales de la Universidad de Durham (Inglaterra). Investigador del Grupo de Integración Regional (GRUDIR) de la Universidad de los Andes, Mérida (Venezuela). 
sustitución de importaciones por la ausencia de una política de protección racional. Se criticaba que el nivel medio de protección era mucho más elevado que el necesario para estimular una efectiva ISI y que la protección para cada producto o grupo de productos no reflejaba un orden de prelación en el que el desarrollo inicial de ciertas industrias era parte de un programa racional, que sería profundizado en etapas posteriores. La CEPAL también rechazaba la ausencia de selectividad en la concesión de la protección arancelaria, causa fundamental de la poca competitividad industrial de América Latina, que conspiraba contra los objetivos de lograr un incremento de la productividad y una mayor difusión del progreso técnico.

La integración regional ayudaría a resolver estos problemas al racionalizar los altos niveles tarifarios en el intercambio entre los países latinoamericanos, mediante una reducción gradual de las barreras al comercio de manufacturas lo que, a su vez, provocaría una mayor competencia intra-industrial. Para ello se recomendaba firmar acuerdos de integración y complementación industrial entre las grandes industrias sustitutivas de importaciones, que provocarían un desplazamiento de los proveedores extra-regionales por productores regionales, promoviéndose así la actividad industrial e impulsándose la modernización de las plantas existentes.

Estos acuerdos de complementación industrial constituían la etapa inicial de la estrategia regional para resolver el problema de la baja competitividad industrial que, una vez incrementada por la creciente competencia intra-latinoamericana, permitiría exponer a las manufacturas regionales en los mercados mundiales. Este planteamiento, muchas veces intencionalmente olvidado, fue reiterado por la CEPAL desde fines de la década de los cincuenta. En 1959 se señalaba que, como consecuencia de la reducción de los costos ocasionados por la competencia en el mercado común, podría desarrollarse nuevas líneas de producción industrial en un ámbito menos proteccionista para ser exportadas al resto del mundo (CEPAL, 1959: 8-9). Prebisch criticó la industrialización cerrada y el proteccionismo excesivo por haber "creado una estructura de costos que dificultaba de sobremanera la exportación de manufacturas al resto del mundo" (Prebisch, 1963: 87). Varios informes de la CEPAL reiteraban estas objeciones a la industrialización existente, en particular su excesiva orientación nacional que había excluido otras modalidades de sustitución adaptadas a "mercados que abarcaran varios países de América Latina o combinados con la exportación de manufacturas hacia fuera de la región” (CEPAL, 1974: 29).

\section{EL MERCADO COMÚN CENTROAMERICANO (MCCA) Y EL MODELO DE DESARROLLO CEPALINO}

Estas ideas de la CEPAL inspiraron las primeras propuestas teóricas sobre integración en América Central durante la década del cincuenta. La CEPAL, que estableció una sub-sede en Ciudad de México en 1951, promovió la integración de los países del istmo mediante la localización ópti- ma de industrias en cada país. Para esto recomendaba que las nuevas plantas tuvieran un régimen de libre comercio, sin el cual no aprovecharían las ventajas de la localización óptima y los menores costos resultantes de establecer industrias regionales (CEPAL, 1951 [1976]: 30). Sin embargo, la liberalización comercial no era el objetivo esencial en el proyecto de la CEPAL sino que se propugnaba una interdependencia entre la política comercial y la industrial. El libre comercio se justificaba sólo como parte de un programa para crear y ampliar plantas industriales (CEPAL, 1951 [1976]: 32), es decir, era válido sólo en la medida en que contribuyese con el programa de industrialización, permitiendo que las manufacturas regionales circularan libremente en el istmo. Como los bienes extra-regionales aún tenían tarifas aduaneras, el libre comercio permitiría a las industrias centroamericanas ser más competitivas a escala regional.

Sin embargo, en la evolución del Mercado Común Centroamericano (MCCA) se produjo una mezcla de ISI, propuesta por la CEPAL, con una política de industrialización con sustitución de exportaciones (ISE). Es importante observar la distinción conceptual entre la promoción de exportaciones (PE) y la ISE. Esta última enfatiza la producción de manufacturas para los mercados mundiales como sustitutas de las producciones agromineras tradicionales (Flores, 1979: 150). De acuerdo a Bulmer-Thomas (1989: 68) en la ISE, se efectúa un desmantelamiento de la estructura nacional de protección, reduciendo los aranceles y depreciando del tipo de cambio nominal para incrementar las exportaciones extra-regionales. En la PE, en cambio, se mantiene la estructura nacional de protección y, a la vez, se promueve la diversificación de las exportaciones. En el MCCA se combinaron la ISI en el ámbito regional con la ISE a escala nacional, una estrategia poco racional ya que "casi por definición, una ISE supone una ISI negativa o inversa porque, en la práctica, la mayoría de los instrumentos que favorecen a una estrategia discriminan contra la otra" (Bulmer Thomas, 1989: 72).

El MCCA nació como un modelo que privilegiaba la ISI regional para crear un aparato industrial que aprendería a ser competitivo en la zona y luego sería expuesto a la competencia internacional. Primero se produciría para el área integrada y luego, cumplida esta fase, para los mercados mundiales, combinando así la ISI con la PE. Sin embargo, en la práctica la ISI fue deformada en el MCCA y no pudo transitar a la fase de la producción para los mercados mundiales, siendo esto último fomentado por políticas nacionales de ISE.

La integración productiva en el MCCA tuvo significativas limitaciones. Ciertamente, el grado de industrialización se incrementó de $13,9 \%$ en 1960 a $17,5 \%$ en 1970 , observándose una creciente complejidad en la producción manufacturera (Ortiz Rosales, 1991). El problema fue que este desarrollo industrial resultó de una política de incentivos fiscales que acrecentó la tasa efectiva de protección a niveles mayores que los otorgados por el arancel externo común. Estos incentivos permitieron el establecimiento de industrias con poco valor agregado regional, que vendían sus bienes de forma segura en el MCCA. Se creó así un sesgo antiexportador pues los industriales optaron por producir para 
el mercado regional, recibiendo incentivos y protegidos por el arancel externo común, en vez de promover exportaciones extra-regionales. Esto conspiró contra la propuesta cepalina de utilizar a la integración como una fase de transición para mejorar la competitividad industrial y para preparase para la competencia global. Al contrario, la industrialización en el MCCA terminó creando plantas ineficientes con una alta capacidad ociosa que, por desarrollarse en condiciones monopolísticas, no aprovecharon las economías de escala y no lograron expandirse sin afectar a los consumidores y a las exportaciones extra-regionales (García, 1988).

La creación de este aparato industrial ineficiente y protegido no es atribuible por lo tanto al modelo cepalino. El RICI no proponía un programa de incentivos fiscales y, en consecuencia, éstos fueron otorgados por cada gobierno de acuerdo a sus prioridades económicas, lo que originó una guerra de incentivos entre los Estados centroamericanos. Por otra parte, es necesario recordar que el RICI perdió importancia en el programa de industrialización centroamericano, siendo sustituido de hecho en 1963 por el llamado "Sistema Especial de Promoción de las Actividades Productivas". Mientras en el RICI se planteaba un desarrollo industrial gradual y recíproco dentro de un régimen de integración, en el Sistema Especial se dejaba la industrialización en manos del mercado previendo que una vez que una nueva industria pudiese cubrir al menos 50\% de la demanda regional debería recibir protección arancelaria. Como es lógico, los inversionistas, mayoritariamente extranjeros, optaron por el Sistema Especial, con el resultado que un proceso con aspiraciones autonómicas terminara protegiendo a industrias de propiedad foránea y altamente dependiente de insumos extra-regionales (García 1988).

A fines de la década del sesenta era evidente el agotamiento de la etapa fácil de la ISI, es decir el período de produción de bienes industriales de consumo, y se debía transitar a la producción de bienes de capital, lo que suponía un mercado ampliado y mayores exigencias de recursos, elementos no existentes en los países del istmo. La respuesta a esta situación no fue regional sino nacional porque los países centroamericanos intentaron diversificar sus exportaciones hacia el resto del mundo para incluir a las manufacturas en su oferta exportable, iniciando una estrategia de ISE. Esta no pretendía utilizar a los mercados extra-regionales en la fase de producción de bienes de capital sino continuar con la etapa fácil de la ISI, enviando parte de la producción industrial fuera de la región. Se produjo entonces una mezcla de la ISI con la ISE con resultados bastante decepcionantes ya que, aunque la estrategia tuvo éxitos en sus inicios, contribuyendo al crecimiento de la producción manufacturera centroamericana, no logró promover la diversificación industrial (Briceño Ruiz, 1999).

De esta forma colapsó la estrategia ISI regional+ISE nacional. Por una parte, la etapa de producción de bienes de capital mediante la ISI no pudo continuarse de forma adecuada en el MCCA pues la estrechez del mercado regional impedía el establecimiento de industrias con escala mínima. Por otra parte, la crisis que sufrió el régimen de libre comercio del MCCA desde mediados de los setenta fue otro factor que contribuyó en el colapso de la estrategia ISI+ISE.
El incremento en el comercio intra-centroamericano había sido el gran logro del MCCA y había permitido garantizar un mercado seguro a los bienes industriales de consumo producidos dentro del programa de integración. El cierre de estos mercados lesionó los planes de desarrollo y expansión de las industrias regionales.

La ISE, por su parte, fue afectada por la crisis económica mundial originada por el incremento en el precio del petróleo en 1973. La recesión mundial que se originó entonces causó una disminución de la demanda de bienes tradicionales centroamericanos en los países desarrollados, de los cuales se obtenían las divisas para financiar el desarrollo manufacturero. La recesión provocó también una contracción de la demanda de manufacturas centroamericanas en los mercados internacionales, que fueron afectadas por el creciente proteccionismo de los países del norte. Esto limitó en gran medida los resultados de la estrategia de ISE y las exportaciones extra-regionales declinaron en forma significativa para todos los países después de 1975.

El establecimiento de la Iniciativa para la Cuenca del Caribe (ICC) en 1983 y la crisis de la deuda externa (1982) desvalorizaron aún más la estrategia de integración centrada en el mercado regional. La ICC, programa unilateral de concesiones comerciales para los países de América Central y el Caribe Insular creado por el gobierno de Ronald Reagan, permitió que varias economías centroamericanas se consolidaran como una especie de paraíso para establecer industrias de procesamiento importación-exportación o maquiladoras. Estas se caracterizan por importar la mayoría de sus insumos, procesarlos en las plantas locales y luego re-exportarlos, sin que se produzca un eslabonamiento o conexión (linkages) entre las industrias locales y las de exportación. Ciertamente, este tipo de industrias ha permitido una diversificación de la oferta exportable manufacturera de la región, sin embargo, como sólo desarrollan la etapa intermedia de un proceso de producción internacional verticalmente integrado que no se inicia ni termina en el Caribe, estas industrias no generan mayores beneficios. Estos se limitan a un aumento en el empleo de salarios de bajos costo y el aumento de las ganancias para los intermediarios locales de las compañías extranjeras (Pantojas, 1986: 56). En consecuencia, el incremento en las exportaciones manufactureras no estimuló el crecimiento de las industrias locales y tampoco causó una expansión del mercado interno.

La crisis de la deuda también ayudó a consolidar la estrategia ISE. Los problemas de financiamiento externo obligaron a los países de la región a privilegiar los mercados extraregionales para poder obtener divisas y cumplir con los compromisos de la deuda. Esto se acompañó con una restricción del intercambio intra-regional para ahorrar divisas y el comercio que se mantuvo debió pagarse en efectivo y no mediante los mecanismos de pagos existentes, como la Cámara de Compensación Centroamericana. Estos dos factores ocasionaron una disminución marcada del comercio intra-zonal en el primer lustro de la década del ochenta en el MCCA que, debido al alto porcentaje de bienes industriales regionales que incluía, afectó aún más la estrategia de integración productiva. 
Además los países de la región debieron implementar programas de ajuste económico recomendados por el Fondo Monetario Internacional (FMI) y el Banco Mundial (BM), los cuales incidieron en el diseño de los esquemas de integración. Estos últimos terminaron adaptándose a la filosofía neoliberal de los programas de ajuste, expresión de lo cual es el Plan de Acción Económica Centroamericana (PAECA), que reformuló en 1991 la integración del istmo. En éste se recogieron las recomendaciones del FMI y el BM, eliminándose el sesgo programador de los esquemas iniciales de integración e implementándose un modelo que enfatiza la inserción internacional y la apertura comercial indiscriminada. La aceptación de este modelo significó el abandono formal del proyecto de integración inspirado en las ideas de la CEPAL, aunque en los hechos éste había sido abandonado mucho años atrás.

\section{LA RELACIÓN ENTRE INTEGRACIÓN Y DESARROLLO EN LA PROPUESTA NEO-ESTRUC- TURALISTA: EL REGIONALISMO ABIERTO}

A mediados de la década del ochenta comenzó una revisión de las ideas cepalinas que intentó presentar un modelo de desarrollo alternativo al neoliberalismo predominante (Sunkel 1991; Rosales 1985). Esta nueva corriente del estructuralismo latinoamericano, denominada neo-estructuralismo, reconoce la importancia de las exportaciones como motor del crecimiento y de la mejora de la balanza comercial. Este esfuerzo exportador debe ser en especial en sectores de elevado valor agregado, lo que implica "un cambio en la base productiva, que acentúe la especialización y la selectividad", algo que a su vez supone elaborar "planes de mediano y largo plazo para la inversión, el desarrollo tecnológico, la formación de recursos humanos y la organización para el comercio externo" (Bitar, 1988: 50). En consecuencia, se recomienda una política arancelaria menos proteccionista que en pasado pero aplicada de forma programada, selectiva y discriminada. De igual manera, se requiere de una tasa de cambio que estimule las exportaciones y cuyo valor sea relativamente estable (Bitar, 1988: 20). Por otra parte, el neo-estructuralismo rechaza programas de liberalización intensa y repentina, pues considera que conducen a la alta ineficiencia. En vez de ello propone una transformación lenta y gradual de la base productiva, lo que supone modificaciones de productos y procesos, inversiones, adaptaciones técnicas, humanas y organizativas.

Para el neo-estructuralismo es necesario un tipo de especialización en el que la estructura productiva esté articulada y permita la interacción de los diversos sectores (ingeniería, informática, electrónica, metalmecánica, bienes de capital, química, investigación tecnológica y formación de mano de obra). Esto se logra fomentando un proceso de industrialización selectiva y articulada con los recursos naturales disponibles que permita inducir mejoras tecnológicas, de calidad en la gestión y en los recursos humanos, factores considerados claves para el crecimiento y la competitividad (Bitar, 1988: 52-53).
El neo-estructuralismo acepta que es necesario revisar el papel del Estado y conceder mayor relevancia al sector privado en el proceso productivo pero considera inadecuadas las propuestas neo-liberales que minimizan al Estado como actor económico. En vez de excluirse al Estado, lo que se requiere es otorgarle nuevas funciones acordes al cambiante contexto mundial y regional, como la dirección del ajuste estructural o el resguardo de la equidad. Por otra parte, el neo-estructuralismo tampoco comparte el optimismo neoliberal sobre la conducta del sector privado como agente dinámico que responde a las indicaciones del mercado y conduce a un incremento de las inversiones y de la ineficiencia. Como señala Bitar (1988:59), la experiencia latinoamericana no confirma la validez de este argumento, pues "sólo en contadas excepciones la liberalización ha hecho surgir en éste [el sector privado] una actitud de innovación y esfuerzo con una perspectiva de mediano plazo".

La propuesta de una transformación productiva con equidad es la respuesta neo-estructuralista al neoliberalismo. De acuerdo con este planteamiento, la incorporación y la difusión del progreso técnico son elementos fundamentales para que una región pueda incrementar su productividad, insertarse de manera exitosa en la economía mundial y asegurar un crecimiento constante. Una transformación productiva con equidad supone el desarrollo de una competitividad auténtica que no se apoye solamente en los salarios bajos o la depredación ambiental, sino que también promueva la formación de recursos humanos y que tenga "la capacidad de agregar positivamente valor intelectual y progreso técnico a su base de recursos naturales, resguardándolos y enriqueciéndolos" (Ottonne, 1993: 389). Dentro de esta misma perspectiva, el neo-estructuralismo propone un modelo de crecimiento desde adentro, es decir, una estrategia de desarrollo industrial que no esté volcada de forma exclusiva a los mercados internos, sino que también se plantee conquistar ciertos mercados externos. Esto debe ser parte de una estrategia a largo plazo para poder alcanzar niveles de excelencia relativa que garanticen una sólida inserción en a economía mundial (Sunkel, 1991; Zuleta, 1992).

La integración servirá para fortalecer el proceso de incorporación y difusión del progreso técnico disponible en el mundo. Al favorecer la ampliación de los mercados y favorecer las vinculaciones entre empresas, sectores e instituciones a nivel sub-regional y regional, la integración ayuda en grado decisivo a promover un proceso de transformación de las estructuras productivas de la región (CEPAL, 1990: 166). De igual manera, la integración también contribuye al éxito de la política de desarrollo desde adentro al permitir una estrategia de liberalización comercial conjunta de los países de la región. Se trata de crear nuevas ventajas comparativas en determinados sectores mediante la acción regional y el crecimiento del comercio intra-zonal "particularmente de los bienes y servicios resultantes de aquellas industrias sustitutivas de importaciones que, ante la eliminación de las distorsiones generadas por el nivel y estructura del sistema tradicional de protección, se convierten en industrias potencialmente exportadoras" (CEPAL, 1990: 167).

En el documento "El Regionalismo Abierto en América Latina y el Caribe. La Integración Económica al Servicio de 
la Transformación Productiva con Equidad", publicado en 1994, la CEPAL delineó las líneas generales de lo que sería la nueva estrategia de integración de América Latina. El documento señala que en los últimos años se ha producido una dualidad en las políticas de integración de los diversos países de la región. Por un lado, han proliferado un conjunto de acuerdos comerciales intergubernamentales en los que se promueven la desgravación arancelaria con el objetivo de crear zonas de libre comercio y, en algunos casos, se plantea la creación de un arancel externo común en el marco de una unión aduanera. Otras iniciativas de integración incluyen la regulación de las inversiones, propiedad intelectual y el desmantelamiento de las medidas para-arancelarias. La CEPAL describe a esta dinámica como una integración impulsadas por políticas. Paralelo a esta modalidad de integración existe lo que la CEPAL denomina integración de hecho. Esta última sería aquella que ha emergido bajo el influjo de un conjunto de políticas macro-económicas y comerciales que, sin ser discriminatorias con respecto al comercio con terceros países, han tenido por efecto la creación de condiciones similares en un número creciente y ya mayoritario de naciones de la región alentando así el comercio y la inversión recíprocos (CEPAL 1994).

El regionalismo abierto es el proceso resultante de conciliar la integración por políticas y la integración de hecho. Según la CEPAL: "se denomina regionalismo abierto al proceso que surge de conciliar... la interdependencia nacida de los acuerdos especiales de carácter preferencial y aquella impulsada básicamente por las señales del mercado resultantes de la liberalización comercial en general" (CEPAL, 1994: 13). Tratando de evitar confusiones entre el regionalismo abierto y apertura indiscriminada, la CEPAL señala que el primero incluye un ingrediente preferencial, reflejado en los acuerdos de integración y reforzado por la cercanía geográfica y la afinidad cultural de los países de la región (CEPAL, 1994: 13).

$\mathrm{Al}$ promover un regionalismo abierto los países latinoamericanos perseguirían compatibilizar la políticas formales de integración económica con las políticas tendientes a elevar la competitividad internacional de los países. En este sentido, la integración sería un complemento de las políticas aperturistas dirigidas a promover una mejor inserción de los países latinoamericano en la economía mundial, dejando de lado las viejas políticas de crecimiento hacia adentro. En otras palabras, "el regionalismo abierto puede ser entendido como un camino 'no multilateral' para avanzar hacia un sistema internacional de comercio más abierto. Esta visión del regionalismo puede interpretarse como aquella integración que no constituye murallas ni tiende a convertirse en una fortaleza aislada del resto del mundo" (Cisneros y Campell, 1996).

Un verdadero regionalismo abierto supone no sólo la liberalización del comercio y las inversiones sino también medidas de ajuste estructural, la integración de los mercados domésticos, inversiones en infraestructura, políticas para promover la difusión de las tecnologías e incrementar la productividad y medidas para asistir a los grupos menos favorecidos (Reynolds et al., 1995: 177). Estas medidas requieren implementarse de forma conjunta para poder ser efectivas en la promoción de la transformación productiva de la región. En la realidad estas políticas están ausentes en buena parte de los esquemas en marcha, con la posible excepción del MERCOSUR.

\section{EL NUEVO REGIONALISMO Y DESARROLLO ECONÓMICO CENTROAMERICANO}

La nueva etapa de la integración centroamericana se orienta más por premisas neo-liberales que por las propuestas neo-estructuralistas. Este proceso de relanzamiento de la integración del istmo acontece en el marco de la apertura comercial de la región impuesta por el Consenso de Washington. La receta consiste en una disminución de las tarifas para reducir el sesgo anti-exportador, sacrificando el arancel externo común, si es necesario, para alcanzar las rebajas requeridas. Se propone el mantenimiento de un tipo de cambio que permita hacer competitivas a las exportaciones centroamericanas. Se recomienda una reforma fiscal que favorezca más a las importaciones no tradicionales hacia el resto del mundo que la exportación de manufacturas hacia la región. Finalmente, se favorece las inversiones en sectores dirigidos a las exportaciones hacia el resto del mundo, en vez de inversiones en infraestructura. En este contexto de libre mercado, la nueva integración promueve la eliminación de cualquier distorsión de la estructura productiva, como los subsidios, las tasas preferenciales de interés, las exenciones fiscales, que serán sustituidas por la lógica de la eficiencia, calidad y productividad implícita en un mercado libre (Fernández Arias y Abarca Amador, 1995: 11-12).

La integración económica centroamericana fue relanzada en la década del noventa apoyándose en este enfoque aperturista, plenamente coincidente con las políticas de ajuste estructural de corte neoliberal implementadas a escala nacional por los diversos países de la región. El punto de partida de esta nueva etapa fue la VIII Reunión de Presidentes del istmo celebrada en junio de 1990 en Antigua, Guatemala, en la que se aprobó el PAECA. Este fue el inicio de una nueva etapa en la integración regional en Centroamérica caracterizada por el desmontaje arancelario y el crecimiento del comercio intrazonal.

En cuanto al régimen comercial se ha producido una reducción arancelaria radical mediante políticas unilaterales o regionales. Desde 1985 todos los países emprendieron programas de ajuste estructural que han tenido como resultado el establecimiento de topes arancelarios entre $20 \%$ como techo y $5 \%$ como piso. Esto ha producido una creciente convergencia arancelaria regional en esos niveles, sustituyéndose el arancel externo común por uno menos proteccionista que en el pasado. El arancel comprende sólo cuatro tasas: $5 \%$ para maquinarias, materias primas y bienes intermedios no producidos en la región, 10\% para maquinarias, materias primas y bienes intermedios producidos en la región, $15 \%$ para bienes de consumo final no producidos en la región y, $20 \%$ para bienes finales producidos en la región (Isa Contreras, 1992: 104). Estos niveles fueron reducidos aún más en 1995 cuando se estableció un arancel de $1 \%$ para los bienes de capital y más tarde, en 
diciembre de mismo año, se autorizó una reducción arancelaria de $0 \%$ para las materias primas y $15 \%$ para bienes de consumo finales. Noventa y cinco por ciento de los rubros arancelarios son uniformes, $2 \%$ están en proceso de unificación y el $3 \%$ restante son tarifas nacionales para productos con un importante contenido fiscal (Briceño Ruiz, 1998).

Esta convergencia en el desarme arancelario explica el sustancial incremento del intercambio intrarregional centroamericano que creció entre 1991 y 1995 de 828.9 millones de dólares a 1.741.1 millones. En 1991 las exportaciones intrarregionales representaron alrededor de $21 \%$ del volumen total de la región, cifra que equivale al comercio registrado con los países de la Unión Europea (Pavel Isa, 1997: 26). Datos de la SIECA señalan que entre 1993 y 1998 el comercio intra-zonal aumentó de 1.160 millones de dólares a 2.237 millones, confirmando la tendencia alcista a lo largo de la década de los noventa (ver cuadro 1).

Cuadro 1

Cuadro 1
Exportaciones intraregionales en Centroamérica. 1991-1998

\begin{tabular}{|l|c|c|c|c|c|c|c|c|c|}
\hline País & 1990 & 1991 & 1992 & 1993 & 1994 & 1995 & 1996 & 1997 & 1998 \\
\hline Costa Rica & 134.5 & 177.6 & 248.3 & 269.4 & 285.8 & 349.6 & 384.2 & $430.9(\mathrm{E})$ & $494.3(\mathrm{E})$ \\
\hline El Salvador & 176.7 & 197.3 & 263.7 & 310.0 & 341.8 & 427.2 & 455.0 & $578.4(\mathrm{P})$ & $612.9(\mathrm{P})$ \\
\hline Guatemala & 288.1 & 323.6 & 395.3 & 418.2 & 474.9 & 554.6 & 577.9 & $683.3(\mathrm{P})$ & $764.9(\mathrm{E})$ \\
\hline Honduras & 24.1 & 32.1 & 48.1 & 105.2 & 139.9 & 180.8 & 206.3 & $213.0(\mathrm{P})$ & $232.8(\mathrm{E})$ \\
\hline Nicaragua & 47.5 & 51.3 & 41.6 & 57.1 & 83.9 & 83.0 & 101.1 & $121.2(\mathrm{P})$ & $232.8(\mathrm{E})$ \\
\hline Total & 670.9 & 781.9 & 670.9 & 11599 & 13.263 & 159.52 & 172445 & $20.268(\mathrm{P})$ & $22.368(\mathrm{E})$ \\
\hline
\end{tabular}

(P'): cifras preliminares. (E): cifras estimadas.
Fuente: Dirección Gencral de Informática, SIECA.

Sin embargo, la desgravación arancelaria y la promoción de una estrategia exportadora basada en el supuesto de las ventajas comparativas regionales no garantizan una adecuada inserción de la región a la economía mundial. Una estrategia de desarrollo que promueva la inserción internacional depende no sólo de las ventajas comparativas sino, y de forma crecientemente importante, de las ventajas competitivas de la región. Estas derivan cada vez más de "factores no precios", es decir, que no se pueden crear mediante la sola corrección de los precios relativos a través de una política de desgravación arancelaria. En vez de ello, la nueva competencia exige políticas estatales de fomento dirigidas a incorporar el progreso técnico, mejorar la calidad de los recursos humanos, fortalecer la base empresarial y aumentar los ingresos y el bienestar de la población (Fürst, 1993: 51).

El aporte de la nueva estrategia de integración al desarrollo del istmo tiene severas limitaciones y merece ser revisada en el contexto de un debate, ya viejo en la región, sobre la contribución de las estrategias aperturistas al desarrollo de los países centroamericanos y el papel que puede desempeñar la integración en tal modelo. En primer lugar, considerar que la simple apertura económica es una vía expedita hacia el desarrollo económico supone soslayar las experiencias de la región en cuanto a los límites de la ISE y, además implica no adaptarse a los cambios en la economía mundial. La experiencia demuestra que la mera apertura y el fomento de la industrialización basándose en la abundancia de mano de obra barata producen resultados positivos sólo de forma temporal pues, como señala Griffith (1990: 37-38) para referirse a la CARICOM, una vez que el costo del factor trabajo se incrementa, si los inversionistas lo consideran excesivo se retiran a otros sitios. Esto puede obligar a los gobiernos a aplicar políticas como la devaluación de la moneda para mantener los salarios bajos y perder la "competitividad”. El problema es que tales políticas terminan teniendo un efecto negativo en la demanda de manufacturas regionales, debido al bajo ingreso de la población, lo que constituye el cuello de botella de la estrategia de ISE (Griffith, 1990: 38).

Por otra parte, aunque se ha producido un incremento sustancial en el intercambio intrazonal como resultado de la desgravación arancelaria implícita en los programas de apertura, esto tiene sus límites. Como señala Bruton (1998: 932), así como se puede hablar de una etapa fácil de sustitución de importaciones también se puede distinguir un período fácil en la estrategia de crecimiento hacia afuera. En economías en las que existen grandes distorsiones de precios, capacidad sub-utilizada, inflación creciente y significativos desequilibrios de balanza de pagos, la corrección estos problemas puede ocasionar un incremento en el producto y una mejora gradual en la productividad de los factores. Esta estrategia se puede continuar durante cierto tiempo, especialmente si existe una etapa expansiva en el comercio mundial. Sin embargo, como se pregunta Bruton, ¿Qué sucede luego que esta etapa fácil se ha agotado y otros factores más significativos entran en juego?. La respuesta es que "si en todos los países eliminan las distorsiones..., el rol del gobierno es mínimo, no existe inflación en ninguna parte, el ahorro y la inversión son equivalentes al menos al $15 \%$ del producto interno bruto y el comercio mundial se expande, ¿crecerían todos los países al ritmo que Corea y Taiwan lo han hecho en las últimas décadas?. La respuesta sería seguramente no" (Bruton, 1998: 932). En otras palabras, la estrategia aperturista puede colapsar alcanzado cierto grado en su desarrollo.

De igual manera, es importante precisar que no se trata de simplemente de fomentar todas las exportaciones sino ciertas exportaciones de "alta tecnología" que incorporen nuevos conocimientos. En este sentido, es crucial entender que debe existir una simbiosis entre las exportaciones y el aprendizaje a escala doméstica. En general entre quienes apoyan la estrategia exportadora predomina la idea de que las producciones de los países en desarrollo al someterse a la competencia extranjera dan un salto en su desarrollo tecnológico para convertirse en internacionalmente competitivas. Sin embargo, existe una fuerte evidencia en contra de este supuesto. La experiencia señala que en vez de producirse un salto a un estado superior de desarrollo tecnológico, lo que sucede es que las empresas que se someten a la competencia internacional deben atravesar por un difícil proceso de adaptación. En este proceso desempeñan un papel fundamental elementos como la organización empresarial, las instituciones, los valores, los incentivos sociales, el compromiso con el crecimiento y otras serie de factores que definen a una sociedad (Bruton, 1998: 930).

Las inversiones extranjeras también juegan un rol importante en este proceso en la medida en que contribuyan a mejorar los procesos tecnológicos y la calidad de los productos. Esta ha sido la estrategia de desarrollo de los países del sudeste asiático que han implementado un modelo de promoción de las inversiones extranjeras que ha incluido la 
transferencia de tecnologías dentro de la región, un proceso en el cual los países ricos localizan sus inversiones y traspasan tecnologías a los más pobres, que añaden éstas en sus nuevas exportaciones. En consecuencia, "El objetivo básico no es atraer inversiones extranjeras como tal, sino crear un ambiente social y económico dentro del cual el proceso nacional de acumulación de conocimiento se beneficie de la presencia de firmas foráneas" (Bruton, 1998: 930). Esto no ocurrió en el MCCA en el que la inversión extranjera tan sólo fomentó industrias de "toque final", con insumos importados que se limitaron a aprovechar el mercado cautivo y a beneficiarse de los incentivos fiscales otorgados, sin contribuir mayormente al progreso tecnológico de la región.

También es necesario reexaminar la posibilidad de establecer alguna forma de control a ciertas importaciones. Este último aspecto genera un enorme debate actualmente debido al predominio de las ideas que se oponen a cualquier forma de regulación de las importaciones o protección arancelaria. Sin embargo, si se reconoce que la apertura no genera un salto inmediato en el aprendizaje tecnológico y la competitividad de las empresas sino que es necesario un proceso de transición, entonces se requiere alguna forma de protección en esta etapa. Así ocurrió en Corea, Japón y Taiwan, cuyos gobiernos han aplicado siempre numerosas formas de protección para inducir el proceso de aprendizaje. En consecuencia, el elemento crucial de la política económica es diseñar medidas de protección que induzcan al aprendizaje más que a la apertura fácil (Bruton, 1988: 930).

De igual manera, debe reconsiderarse un nuevo rol del Estado en el proceso de integración. Es cierto que en décadas anteriores los gobierno latinoamericanos se mostraron poco eficientes en el manejo de los asuntos económicos, pero esto no permite concluir que el Estado sea per se ineficiente. Como señala Bruton (1998: 931, "el papel que los gobiernos pueden desempeñar depende... de las instituciones, la historia y la cultura de la comunidad. Que algunos gobiernos son letales, que muchos son ineptos y descuidados es algo ampliamente reconocido, pero hay muchas cosas que sólo puede hacer un gobierno." El rol del gobierno en el proceso de aprendizaje tecnológico debe ser una prioridad en la política pública y debe intensificarse en vez debilitarse mediante políticas que busquen minimizar el Estado.

\section{CONCLUSIÓN}

El análisis del proceso de integración en América Central y de las críticas recientes al modelo de desarrollo fundamentado en la mera apertura recomiendan replantear el debate sobre cual es el aporte real de la integración a las políticas de desarrollo. Se requiere un nuevo modelo de inserción internacional que combine la tradición prebischiana con políticas de promoción de exportaciones (ISI+PE). Una estrategia de este tipo tendría dos propósitos: romper la asimetría derivada de la distinta elasticidad-ingreso de la demanda de productos básicos y manufacturas y aprovechar las externalidades positivas de la industrialización en cuanto a la propagación del progreso técnico, mejora de las destrezas laborales e incremento de la productividad y del nivel de vida a largo plazo (Salazar, 1993: 29).
La ruptura de la asimetría de la elasticidad-ingreso de la demanda de bienes primarios y manufacturas requiere una estrategia para fomentar inversiones y desarrollar ventajas competitivas en productos de elevada elasticidad ingreso. Se debería pasar de líneas de producción de bajo crecimiento, incluyendo las exportaciones industriales de contenido tecnológico relativamente bajo, a nuevas áreas de alto crecimiento (Prebisch, 1985: 51). No se trata solamente de promover ciertas líneas de producción sino de lograr que éstas puedan competir internacionalmente $y$, a la vez, fomentar el progreso técnico.

Las propuestas más recientes de la CEPAL que insisten en la necesidad de la incorporación continua del progreso técnico son parte esencial de esta estrategia. Se requiere promover una competitividad auténtica, noción que tiene un aspecto microeconómico y macroeconómico (CEPAL, 1990). En la primera acepción se intenta que los bienes producidos en la región logren sustentar patrones de eficiencia vigentes en el resto del mundo en cuanto a la utilización de recursos y a la calidad del producto ofrecido. En su acepción macroeconómica, exige a las economías nacionales desarrollar la capacidad de incrementar (o al menos sustentar) su participación en los mercados internacionales y, de forma simultánea, promover un alza del nivel de vida de la población Ambas acepciones deberían ser incorporadas en la estrategia de integración que desarrollan los países de centroamericanos. En particular, el énfasis en la promoción de los niveles de vida es considerado vital para desarrollar una competitividad auténtica e implica, al contrario del modelo de ISE, un incremento persistente de los salarios. En las nuevas ideas cepalinas el alza de los salarios es lo que diferencia a la competitividad auténtica de la espúrea y es la manifestación de que está ocurriendo una distribución intensa de los frutos del progreso técnico (Rodríguez et al, 1995: 81-82)

Estos esfuerzos de promoción de nuevos sectores industriales de alto crecimiento, aunque, como señala Salazar (1993), en su fase inicial impliquen un retorno a la ISI, tienen como propósito fundamental conquistar los mercados mundiales e incrementar la competitividad auténtica de las economías de la región. Por ello es preciso eliminar el sesgo proteccionista de la política comercial e implementar una protección selectiva que permita el desarrollo de los sectores de alto crecimiento. Esto exige además de una racional política comercial, una intensiva inversión en investigación y desarrollo, lo cual supone una fuerte participación del Estado en la estrategia de integración y la superación del sesgo anti-estatista de las políticas económicas predominantes en la región.

Un modelo alternativo a la mera apertura comercial debe convertir a integración Centroamericana en un instrumento a favor de la transformación productiva con equidad de las economías del istmo. Una integración de tal tipo requiere la intervención estatal en la creación de externalidades en materia social y de infraestructura, exige la promoción de encadenamientos inter e intra-sectoriales, obliga a desarrollar innovaciones tecnológicas, organizativas y reformas institucionales. "Estas reformas y políticas estructurales y no tanto una corrección del sesgo anti-exportador, medida únicamente por señales de precios liberalizados, podrían garan- 
tizar condiciones para una inserción externa eficiente" (Fürst, 1993: 52).

Este modelo de integración permitiría que las industrias establecidas mediante la política de sustitución de importaciones pudieran cubrir sus costos fijos de producción y exportar a costos marginales. De igual manera, la existencia de un mercado regional podría servir como laboratorio, con menor costo y a bajo riesgo, para las innovaciones en materia tecnológica de productos y procesos. Estos últimos serían sometidos posteriormente a la competencia externa. Además, en un ámbito regional se podría desarrollar acciones conjuntas en pro de una mayor competitividad regional, como esquemas de exportación conjunta, políticas de fomento de las inversiones, inversiones comunes en materia de ciencia y tecnología, coordinación de políticas, etc. La integración también facilita la complementariedad y la especialización para desarrollar en conjunto ventajas competitivas, difíciles de alcanzar por separado. Finalmente, si la integración incluye la acción conjunta regional, cada país podría obtener beneficios imposibles de alcanzar basándose en acciones unilaterales (Salazar, 1993).

Esta serie de propuestas tienen sus raíces en muchos de los viejos planteamientos de Prebisch y la CEPAL sobre los problemas del desarrollo económico latinoamericano y el papel que la integración puede desempeñar en su solución. Ciertamente, las recientes propuestas reconocen que se han producido una serie de transformaciones estructurales en las economías de la región debido al cambio de su modelo de acumulación (Bielschowsky, 1998: 23). Sin embargo, es preciso señalar que aunque la reforma económica es necesaria y puede contribuir al crecimiento económico latinoamericano, su contenido y la forma como se aplica son las variables que van determinar sus resultados finales. En este contexto, es válido reivindicar un modelo de desarrollo que incluya un conjunto de políticas públicas que trasciendan la mera apertura comercial y contribuya a promover de forma más armoniosa el progreso económico de la región. Una integración al servicio de la transformación productiva debería tener un papel significativo en este modelo.

\section{REFERENCIAS}

BIELSCHOWSKY, Ricardo (1998): "Evolución de las Ideas de la CEPAL”, Revista de la CEPAL, número extraordinario, octubre 1998, versión electrónica: http: www.cepal. org/ espanol/RevistaCepal/rvcincuenta/bielchow.htm.

Briceño Ruiz, José (1999): "El Viejo y el Nuevo Regionalismo Caribeño. Un Análisis Comparado de la Teoría y Práctica de las Experiencias de Integración en la Cuenca del Caribe”, en Briceño Ruiz, José (compilador), Escenarios de la Integración Regional en las Américas, (Mérida, Venezuela: Consejo de Publicaciones de la Universidad de los Andes).

- (1998): "La Nueva Integración Centroamericana" Comercio Exterior, (México), 48: 11, pp. 880-887.

BRuton, Henry J. (1998): “A Reconsideration of Import Substitution”, Journal of Economic Literature, XXXVI: 2, (June), pp 903-936.
Bulmer-Thomas, Victor (1989) "Can Regional Import Substitution and Export Led Growth be Combined?", en: Irving, George and Stuart Holland (editor), Central America: The Future of Economic Integration, (LondonBoulder-San Francisco: Westwiew Press), pp. 67-88.

CiSNEROS, Andrés y Jorge CAMPELL, 1996, "El MERCOSUR: Regionalismo Abierto o un Building Block', Boletim de Integração Latino-Americana, (Brasilia), no. 19, (julhodezembro), versión electrónica: http: //www.mre.gov.bt/ geted/WEBGETEC/BILA.

COMisión ECONÓMICA PARA AmÉrica Latina, CEPAL, El Regionalismo Abierto en América Latina y el Caribe. La Integración Económica al Servicio de la Transformación Productiva con Equidad, (Santiago: Naciones Unidas).

- (1990): Transformación Productiva con Equidad, (Santiago: CEPAL).

- (1974), América Latina: Integración Económica y Sustitución de Importaciones, (México: FCE).

- (1959): El Mercado Comín Latinoamericano, (Santiago: ONU).

- 1951 (1976): “Alcance y Requisitos de una Política de Integración y Reciprocidad”, en: Lizano, Eduardo (editor), La Integración Económica Centroamericana, (México: FCE), pp. 29-39.

FERNÁNDEZ ARIAS, Mario E. y Ethel Abarca Amador (1995): “El Protocolo al Tratado General de Integración Económica Centroamericana”, Anuario de Estudios Centroamericanos, (San José), 21: 1-2, pp. 9-37.

FüRST, Edgar (1993): “Centroamérica en los Años Noventa: Libre Comercio e Integración Regional ante el Reto de una Transformación Productiva con Equidad y Desarrollo Sustentable”, Ciencias Económicas, (San José), XIII: 1-2, pp. 45-67.

GARCÍA, Rigoberto (1988): Integración o Desintegración: el Mercado Común Centroamericano, (Estocolmo, Latinamerika Institutet), Informe de Investigación no. 56, junio.

GRIFFITH, Winston H. (1990a): “Integración Comercial del Caribe: Problemas y Perspectivas”, Integración Latinoamericana 15: 163, (diciembre), pp. 15-25.

Isa Contreras, Pavel (1997): Crisis y Resurrección de la Integración Económica en Centroamérica: Logros y Debilidades en un Nuevo Contexto Internacional, Trabajo Preparado Para El Proyecto "Integración y Soberanía Nacional en el Caribe”, Instituto Latinoamericano de Servicios Legales Alternativos (ILSA), Bogotá, Mimeo.

Ortiz Rosales, Rolando Eliseo (1991): "Centroamérica: Consideraciones sobre la Crisis del Proceso de Integración Económica”, Economía. Revista del Instituto de Investigaciones Económicas y Sociales de la Universidad de San Carlos de Guatemala, XXIX:107 (enero-marzo), pp. 1-33.

OtTONE, Ernesto (1992-1993): "La CEPAL: Un Planteamiento Renovado frente a los Nuevos Desafíos del Desarrollo", Pensamiento Iberoamericano, 22-23, (julio 1992-junio 1993), pp. 386-392.

PAnTojA, Emilio (1996): "La Iniciativa para la Cuenca del Caribe y el Modelo Puertoriqueño: una Comparación Necesaria”, Caribe Contemporaneo, 13, (noviembre), pp. 49-69. 
PrebisCH, Raúl (1986): “Crisis Mundial y Nuevas Fórmulas para la Integración”, Integración Latinoamericana, 10:98, (enero-febrero), pp. 50-55.

- (1963): Hacia una Dinámica de Desarrollo Latinoamericano, (México: Fondo de Cultura Económica).

- 1949 (1996): “El Desarrollo Latinoamericano y sus Principales Problemas”, El Trimestre Económico, LXIIII:249), (enero-marzo), pp. 175-245.

- (1959a): "Commercial Policy in the Underdevelopment World", The American Economic Review, XLIX: 2, (May), pp. 251-273.

- (1959b): "El Mercado Común Latinoamericano", Comercio Exterior, IX:9 (septiembre), pp. 509-513.

Reynolds, Clark, Francisco Thoumi y Reinhart Wettman (1995): A Case for Open Regionalism in the Andes. Policy Implications of Andean Integration in a Period of Hemispheric Liberalisation and Structural Adjustment,
September, USAID/ILDIS-Friederich Ebert Stiftung and the North American Forum, Standford University. Rodriguez, Octavio et Al. (1995): "CEPAL: Velhas e Novas Ideas”, Economia e Sociedade, 5 (dezembro), pp. 79-109. Rosales, Oswaldo (1985): "Balance y Renovación del Paradigma Estructuralista del Desarrollo Latinoamericano", Revista de la CEPAL, 34, (abril), pp. 19-36.

SAlazAr, José Manuel (1993): “El Resurgimento de la Integración y el Legado de Prebisch”, Revista de la CEPAL, (Santiago), 50, pp. 21-40.

Sunkel, Oswaldo (Comp.): (1991), El Desarrollo desde Adentro, un Enfoque Noe-Estructuralismo", (México: Fondo de Cultura).

ZulEtA, Gustavo (1992): "El desarrollo desde adentro: un enfoque neo-estructuralista para América Latina”, Pensamiento Iberoamericano, 21, (enero-junio), pp. 304 313.

\section{RESUMEN}

En este ensayo se evalúa el papel que la integración regional ha desempeñado en los programas de desarrollo económico de los países de América Central en los últimos cincuenta años. Esto supone realizar una revisión del proyecto de desarrollo económico elaborado por Raúl Prebisch y la Comisión Económica para América Latina (CEPAL), cuyo núcleo lo constituía la industrialización con sustitución de importaciones. En el ensayo se examina en que medida las ideas cepalinas fueron parte de las políticas de integración que se implementaron en Centroamérica, cómo evolucionó este proceso y cuáles fueron las causas de su colapso. De igual manera, en el trabajo se analiza la nueva etapa aperturista de la integración en el istmo y sus limitaciones para contribuir a la transformación productiva de la región. El ensayo concluye con una serie de reflexiones que plantean un retorno a las viejas ideas cepalinas que conciben a la integración como parte de una estrategia económica cuyas metas fundamentales son lograr una difusión del progreso técnico y un incremento en el bienestar colectivo.

Palabras clave: Integración, CEPAL, Prebisch, Centroamérica, desarrollo.

\section{ABSTRACT}

This paper examines the role of regional integration in the promotion of economic development of Central American countries in the last fifty years. This implies a review of the ideas about development presented by Raul Prebisch and the Economic Commission for Latin America (ECLAC), the cornerstone of which were the promotion of regional industrialisation. This essay evaluates the extent to which ECLAC's ideas about integration were actually implemented in the Central American Common Market. The evolution of this integration scheme and the reason of its collapse are also explained in this paper. Similarly, the new period of regional integration in Central America and its limitations are analysed. The conclusion is the need for a return to some of the old ECLAC's proposals that conceived integration as part of a strategy leading to promote the diffusion of technical progress and the improvement of the collective welfare.

Key Words: Integration, ECLAC, Presbisch, Central America, development. 


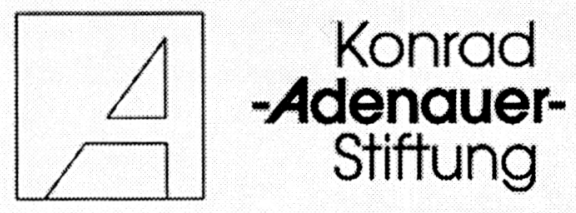

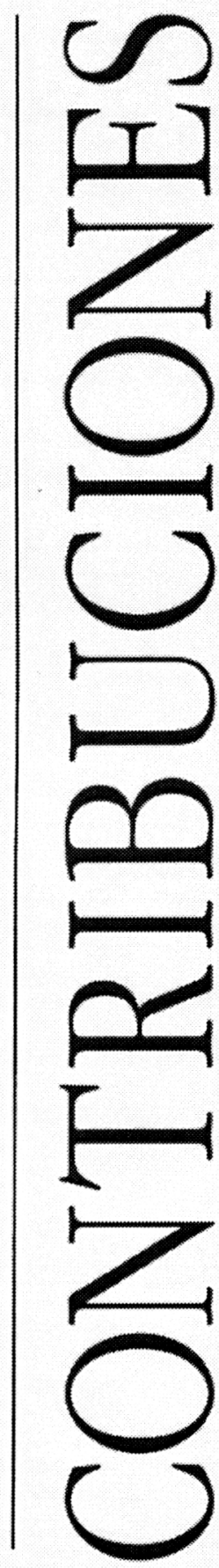

$1 / 1999$

\section{Estado ACTUAL DE LOS PROCESOS DE INTEGRACIÓN}

\section{TEMAS}

Relación entre la Unión Europea y el MERCOSUR Dieter $W$. Benecke

Apuntes sobre escenarios estratégicos de la integración Daniel Scbutt

Los temas no comerciales del ALCA

Jaime Gerardo Delgado Rojas

Relaciones interempresarias en el Mercosur

Ana I. Piaggi

Protección jurídica para los particulares en el Mercosur Dante Marcelo Ramos

\section{ENSAYOS}

Globalización y la división de la soberanía Jonge Edmundo Barbarâ

Aspectos de la reforma del Estado en la Argentína Alberto L. Galfione y Miguel J. Rodriguez Villafañe

Cultura o mercado caribeño Elizabeth Maban y Adolfo Vangas

Globalización y regionalización

María Izabel Mallmann

El Estado y la descentralización en Venezuela Zaira Reverón Escobar

Perfilando la videopolítica Cintia Smitb

\section{DOCUMENTOS Y HECHOS}

Uruguay: Fin de siglo muy electoral Jorge L. Marius y Juan $F_{*}$ Bacigalupe

Elecciones en Venezuela Michael Lingenthal

\section{COMENTARIOS DE LIBROS}

Nuevos libros prevén conflictos por el uso de nueva tecnología en los medios de comunicación Frank Priess 